\title{
Antioxidant Property and Antimicrobial Activity of the Aromatic Plant Balsamita major Desf
}

\section{Cecilia Faraloni}

Trees and Timber Institute, National Research Council, Via Madonna del Piano, Sesto Fiorentino, Firenze, Italy

The new trend to use natural compounds in clinical application has improve numerous studies on the chemical characterization of plant materials extracts, in order to find out application in the medical field, according to the chemical properties of the different extracts. Among aromatic plants, different members of the genus Asteraceae (such as Tanacetum balsamita L.) is known in western Asia area, Mediterranean and Balkan countries, for its therapeutic properties (diuretic, spasmolytic, anti-inflammatory, and antimicrobial activity), which are related to its antioxidant and antimicrobial activity.

Some characterization has been carried out in recent years, on plants of Balsamita major Desf, which is known in Tuscany since the seventeenth century thanks to the work of the Dominican friars of the convent of Santa Maria Novella in Florence [1].

Different kind of leaves extracts have been examined to better identify the compounds associated to these medical properties. In particular, alcoholic (methanol, ethanol) and aqueous extracts have been studied. The main constituents found in both kinds of leaves extracts were polyphenolic compounds, which can be usually found at the highest concentration in the period of June, during which the highest plant productivity is also observed [2]. In the methanol extracts polyphenolic compounds were found to be over $30 \mathrm{mg} / \mathrm{g}$, and were characterized by the presence of caffeic acid, 3,5-O-dicaffeoylquinic acid, apigenin and luteolin. Other components such as cinnamic acid and flavonoids were also present. Also the aqueous extracts, were characterized by a high content in polyphenols, but they resulted 50 fold lower, for the lower power of water extraction. The antioxidant properties of these extracts have been evaluated, in order to better find their possible clinical application. As in the alcoholic extracts the polyphenolic content result the highest, also the antioxidant activity was higher than in the aqueous one. The values for this aromatic plant extracts reached $1500 \mu \mathrm{mol} \mathrm{TE} / \mathrm{g}$ ES, whereas the anti-radical activity was $0.7-1.2 \mathrm{mg} / \mathrm{ml}$. Very interestingly, these values are even better than the ones reported for certain types of fruit (strawberries, blueberries, berries) which are considered a valuable natural source of natural antioxidants $[3,4]$, so by virtue of its antioxidant properties it can be possible to consider the use of this medicinal plant for human health.

Moreover, many studies have been focused on the antimicrobial activity of the essential oils of Costmary [5], which can find several application, such as tonic, sedative, cardiotonic, hepatoprotective, and also used as insecticidal agents [6,7,8,9]. Form ethanolic extracts of some Asteraceae species a considerable antimicrobial activity has been reported, on both Gram-positive and Gram-negative bacteria for example on some S. aureus and B. cereus [10]. These properties can be attributed not only to the presence of polyphenols, but also to the presence of thujones, carvone and pyrethrin $[9,11]$, which are extracted by alcohol at high concentration.

An additive value to this aromatic plant consist in the presence in their leaves of an appreciable carotenoids content. In the period of June, a carotenoid content of $20 \mathrm{mg} / \mathrm{g}$ was found, mainly constituted by the xanthophylls neoxanthin, loroxanthin, lutein, violaxanthin and antheraxanthin, and by $\beta$-carotene.

\section{Publication History:}

Received: October 23, 2018

Accepted: December 26, 2018

Published: December 28, 2018

\section{Keywords:}

Antioxidant, Antimicrobial, Polyphenols, Carotenoids

Considering the antioxidant properties, Balsamita extracts can find application in the cosmetic field, in particular by intervening in the mechanisms of protection against chrono-aging and photo-aging.

\section{Acknowledgment}

The author want to thank Officina Profumo Farmaceutica Santa Maria Novella, for plant material and financial supporting.

\section{Competing Interests}

The author declares that there is no competing interest.

\section{References}

1. Ena A, Nelli M, Pintucci C, Faraloni C, Paperi R, et al. (2009) Antioxidant potential of leaf extract of Balsamita major Desf. J Medicinal Aromatic Plant 31: 228-233.

2. Faraloni C, Bonetti A (2018) Nutraceutic and cosmetic activity of Balsamita major Desf. In Proceedings, Piante Medicinali 17: 47.

3. Prior RG, Cao A Martin E, Sofic J, McEwen Ch, et al. (1998) Antioxidant capacity as influenced by total phenolic and anthocyanin content, maturity, and variety of Vaccinium species. Journal of Agriculture and Food Chemistry 46: 2686-2693.

4. Huang D, Ou B, Hampsch-Woodill M, Flanagan JA, Prior RL, et al. (2002) High-troughput assay of oxygen radical absorbance capacity (ORAC) using a multichannel liquid handing system coupled with a microplate fluorescence reader in 96-well format. J Agric Food Chem 50: 4437-4444.

5. Kubo A, Kubo I (1995) Antimicrobial agents from Tanacetum balsamita. J Natural Products 58: 1565-1569.

6. Zarghari A (1996) Medicinal plants. Tehran University Publication, Iran.

7. Bylaite E, Venscutonis R, Roozen JP, Posthumus MA (2000) Composition of essential oil of costmary [Balsamita major (L) desf] at different growth phases. Journal of Agricultural and Food Chemistry 48: 2409-2414.

8. Abad MJ, Bermejo P, Villar A (2006) An approach to the genus TanacetumL. (Compositae): Phytochemical and pharmacological review. Phytotherapy Res 9: 79-92.

"Corresponding Author: Dr. Cecilia Faraloni, Trees and Timber Institute, National Research Council Via Madonna del Piano n.101, 50019 Sesto Fiorentino, Firenze, Italy; E-mail: cecilia.faraloni@cnr.it

Citation: Faraloni C (2018) Antioxidant Property and Antimicrobial Activity of the Aromatic Plant Balsamita major Desf. Int J Clin Med Microbiol 3: 138. doi: https:// doi.org/10.15344/2456-4028/2018/138

Copyright: (C) 2018 Faraloni. This is an open-access article distributed under the terms of the Creative Commons Attribution License, which permits unrestricted use, distribution, and reproduction in any medium, provided the original author and source are credited. 
Citation: Faraloni C (2018) Antioxidant Property and Antimicrobial Activity of the Aromatic Plant Balsamita major Desf. Int J Clin Med Microbiol 3: 138. doi: https://doi.org/10.15344/2456-4028/2018/138

Page 2 of 2

9. Pérez-Alonso MJ, Velasco-Negueruela A, Burzaco A (1992) Tanacetum balsamita L.: A medicinal plant from Guadalajara (Spain). Acta Horticulturae 306: 188-193.

10. Guven K, Çelik S, Uysal I (2005) Antimicrobial activity of Centaurea species. Pharm Biol 43: 67-71.

11. Teixeira da Silva JA (20014) Mining the essential oils of the Anthemideae. African Journal of Biotechnology 3: 706-720. 